\title{
A Study of Body Image in Young Children: Factors Relating to Body Perception in 4-5 Year Old Children
}

\author{
Insuk Choi ${ }^{1}$, Jisoo $\mathrm{Im}^{2}$ \\ Department of Family and Child Welfare, Wonkwang University, Iksan, Korea ${ }^{1}$ \\ Suwon Court Child Care Center, Suwon, Korea ${ }^{2}$ \\ 유아의 신체상에 관한 연구: 4,5 세 유아의 신체인식에 영향을 미치는 요인 \\ 최인숙 ${ }^{1}$, 임지수 ${ }^{2}$ \\ 원광대학교 가정아동복지학과 ${ }^{1}$, 수원법원어린이집 ${ }^{2}$
}

Objectives: The purpose of this study was to determine the factors relating to body perception in Korean preschool children.

Methods: Participants of this study were obtained from the first year of a short-term longitudinal study conducted in 2016, comprising 97 preschool children( $M=61.8$ months) and their mothers. To investigate the factors relating to children's body perception, we analyzed their individual characteristics, maternal factors, and media exposure. Data were analyzed by correlation and hierarchical regression.

Results: Children with higher media experience showed higher negative body perception. Mothers of children with higher body mass index (BMI) gave more verbal messages on child's weight reduction. Controlling for sociodemographic variables, children's BMI was negatively associated with negative body perception, while mothers' verbal messages on weight reduction was positively associated with negative body perception. Mothers' verbal messages were a more influential factor than children's BMI.

Conclusions: The findings suggest that children's BMI, mothers' verbal messages regarding children's body as well as a mothers' education level and family income level are influential factors in preschool children's body perception.

Keywords: preschool children's body image, body perception, maternal factors, sociocultural factors

$$
\text { 서론 }
$$

한국 사회의 외모지상주의는 성인에게만 국한된 문제는 아니 다. 아동부터 성인까지 외모에 대한 관심과 외모를 중시하는 태도가 그 어느 시기보다 부각되고 있다. 2015년 인천발전연 구원이 인천지역 고등학생 4,600여명을 대상으로 조사한 결 과 남학생 $59.7 \%$, 여학생의 $78.2 \%$ 가 평상시에 스트레스를 받

Corresponding Author: Insuk Choi, Department of Family and Child Welfare, Wonkwang University, Iksan, Korea

E-mail: aneschoi01@wku.ac.kr
고 있으며, 스트레스의 가장 큰 원인은 '성적과 진로에 대한 부 담'을 제외하고 '키나 체형 같은 외모스트레스'가 가장 큰 것으 로 나타났다(Jang, 2016, March 2). 현대사회에서 비현실적인 미의 기준과 이상형이 등장하고 이것에 영향을 받은 아동이 자신의 신체에 대해 불만족스러워할 수 있고 부정적인 신체상 을 형성할 가능성이 높아졌다. 신체상에 관한 선행연구 리뷰 문헌을 통해 Knafo (2016)는 아동기에 부정적인 신체상을 형

\section{(C)The Korean Association of Child Studies}

This is an Open Access article distributed under the terms of the Creative Commons Attribution Non-Commercial License (http:// creativecommons.org/licenses/by-nc/4.0) which permits unrestricted noncommercial use, distribution, and reproduction in any medium, provided the original work is properly cited. 
성하는 것이 이후에 섭식장애, 낮은 수준의 자존감 등 정신건 강문제와 관련이 있는 것으로 보고하였다. 따라서 이른 시기 부터 긍정적인 신체상을 형성할 수 있도록 유아의 신체상에 영향을 미치는 요인을 확인하는 것이 의미가 있을 것이다.

신체상이란 자기 자신의 신체적 외양에 대한 주관적 태 도이다(Slade, 1988). 신체상은 신체와 관련된 사고, 감정, 지 각, 행동을 포괄하는 광범위한 용어로 다차원적 개념으로 간 주될 수 있다. 지금까지 신체상에 대한 선행연구에서는 주 로 자신의 신체적 외모에 대한 태도, 감정, 지각에 초점을 맞 추어 신체상을 신체인식이나 신체만족도 등으로 다루어왔다 (Thompson, Heinberg, Altabe, \& Tantleff-Dunn, 1999). 따라서 본 연구에서는 유아의 신체상을 유아가 자신의 신체에 대해 느끼는 감정이나 인식이라는 관점에서 접근하고자 한다.

아동의 신체상에 대한 선행연구는 국내연구보다는 서구 아동을 대상으로 한 연구가 다수였는데, 신체상은 성별, 연 령, 체중 등의 개인적 요인뿐 아니라 인종과 문화 또한 중요 한 역할을 하는 것으로 나타났다(Dohnt \& Tiggemann, 2006a; Musher-Eizenman, Holub, Edwards-Leeper, Persson, \& Goldstein, 2004; Phares, Steinberg, \& Thompson, 2004; Robinson, Chang, Haydel, \& Killen, 2001; Veldhuis, Te Poel, Pepping, Konijn, \& Spekman, 2017). 예를 들어, 8-11세 아동을 대상으로 한 신체 상에 대한 심리적 불안과 관련 요인을 살펴본 선행연구(Phares et al., 2004)에서는 여아가 남아보다 마른 몸이나 몸무게 등 신 체에 관한 걱정을 더 많이 경험하는 것으로 보고하였다. 또 한 초등학교 3학년 아동이 선호하는 신체상에 대한 선행연구 (Robinson et al., 2001)에서는 흑인 아동이 지각된 자기 신체보 다 더 큰 신체를 선호하는 반면에 백인 아동은 현재의 체격보 다 더 마른 체격을 선호하였다.

한편 유아의 신체상 발달을 살펴본 선행연구에서는 유아 를 대상으로 신체상을 평가하기 위하여 적절한 그림측정도구 를 개발하여 사용함으로써 자기 신체에 대한 주관적 평가가 4-5세에 이미 시작된다는 것을 입증했다. 예를 들어, 3-5세 유 아를 대상으로 신체크기에 대한 인식과 편견을 확인한 선행 연구(Cramer \& Steinwert 1998; Musher-Eizenman et al., 2003) 에서는 유아가 4세 경에 특정한 신체크기에 대한 편견을 드러 낸다고 보고하였다. 유아의 신체상에 대한 편견(Kirkpatrick \& Sanders, 1978; Stager \& Burke, 1982)을 살펴본 선행연구에서는 5 세 유아부터 신체의 크기에 대한 편견이 나타났다. 유아는 보 통 체격의 또래에 대해서는 행복, 친절, 영리함 등의 긍정적인 언어로 표현한 반면에, 통통한 또래에 대해서는 어리석음, 비 열함, 마른 또래에 대해서는 겁쟁이, 약함 등의 부정적인 용어
로 표현하였다. 또한 Tremblay와 Limbos (2009)는 부정적인 신 체상이 청소년기가 되기 전에 나타나며 빠르게는 5-7세 아동 에게서 관찰이 가능하다고 보고하였다.

우리나라 유아의 신체상 발달에 대한 연구는 아직까지는 제한적인 수준이다. 최근 10 년 동안 만 5 세 유아의 신체상에 대한 이해를 살펴본 질적 연구(Park \& Lee, 2010), 5세 유아의 외모에 대한 사회문화적 태도(H.-Y. Kim, Kim, \& Kim, 2012), 유아의 외모 및 체형에 대한 5세 유아의 인식 및 경험 분석(H.J. Kim, Kim, \& Kim, 2012) 등에 그치고 있다. 어린 시기에 형 성된 신체상이 신체자존감과 관련이 있고 이후에 섭식행동과 신체 활동 수준과도 관련이 있는 것(Marsh, Hau, Sung, \& Yu, 2007)을 고려했을 때, 우리나라 유아의 자기 신체에 대한 인식 을 평가하고 이에 영향을 미치는 요인을 살펴볼 필요가 있다.

유아의 신체 인식에 영향을 미칠 수 있는 유아 개인 요인으 로는 유아의 실제 신체 크기이다. 실제 자신의 신체 크기는 유 아가 스스로의 몸에 대해 어떻게 바라보고 평가하는지와 관련 이 있을 것이다. 유아의 성별 또한 신체 인식에 영향을 미칠 수 있다. 성별에 따른 신체상의 차이는 성인을 대상으로 한 연구 에서는 지속적으로 입증되어왔다. 선행연구(Engeln-Maddox 2006; Jang \& Kim, 2006)에 따르면 성인과 청소년 모두 여성 이 남성에 비해 신체에 대한 불만족 수준이 높은 것으로 나타 났다. 그러나 연령이 어린 아동을 대상으로 한 연구에서는 성 별에 따른 차이가 일관되지는 않았다. 6-8세 아동을 대상으 로 한 연구(Collins, 1991; Oliver \& Thelen, 1996; Thelen, Powell, Lawrence, \& Kuhnert, 1992)에서 여아가 남아보다 외모에 대한 관심이 많고 자신의 신체에 대해 불만 수준도 높은 것으로 나 타났다. 반면에 6세 이하의 유아를 대상으로 한 선행연구에서 는 성별에 따른 차이가 없는 것으로 나타났다(Hendy, Gustitus, \& Leitzel-Schwalm, 2001; H. -Y. Kim et al., 2012). 따라서 성별 에 따라 유아의 신체인식에서 차이가 나타나는지 검증될 필요 가 있다.

유아의 신체인식에 영향을 미치는 환경 요인 가운데 가장 중요한 환경은 부모이다. 특히 유아기는 주양육자인 어머니 가 발달에 미치는 영향이 다른 환경 요인보다 큰 시기이며 어 머니와 가장 친밀한 관계를 유지하는 시기이기도 하다. 아동 의 신체상에 영향을 미치는 요인을 살펴본 선행연구에서는 사 회인지 이론(Bandura, 1997)을 기초로 아동이 자신의 신체상 을 형성하도록 모델을 제공하는 중요한 대상인 어머니의 영향 을 고찰하였다(Hendy et al., 2001; Pike \& Rodin, 1991; Sands \& Wardle, 2003; Vander Wal \& Thelen, 2000). 이 가운데 초등학생 이상의 아동과 청소년을 대상으로 한 연구에서는 어머니가 자 
신의 신체에 대해서 만족하는 정도를 의미하는 어머니 자신의 신체상이나 섭식행동, 자녀의 신체에 대한 직접적인 평가 등 이 자녀의 체중조절이나 신체상에 영향을 미치는 것으로 보고 하였다. 반면에 유아를 대상으로 한 Hendy 등(2001)의 연구에 서는 어머니의 자녀의 신체에 대한 평가는 영향을 미치는 요 인이었지만 어머니 자신의 신체상, 즉 자신의 신체에 대한 인 식은 자녀에게 영향을 미치지 않는 것으로 나타났다. 따라서 유아기부터 어머니 자신의 신체인식이나 어머니가 자녀와 나 누는 신체에 대한 언어적 상호작용이 모델링 역할을 하여 유 아가 자신의 신체를 인식하는데 영향을 미치는지 확인할 필요 가 있다.

유아에게 영향을 미치는 환경 요인에는 사회문화적 요인도 포함될 수 있다. 사회문화적 모델(Dohnt \& Tiggemann, 2006a; Thompson et al., 1999)에서 제시하는 사회문화적 요인, 즉 사 회가 요구하는 성별에 따른 신체 기준, 미디어를 통해 경험하 는 미의 기준에 부합한 이상적인 신체 등은 유아가 자신의 신 체에 대해 느끼는 감정이나 태도에 영향을 미칠 수 있을 것이 다. 문화산업의 성장에 힘입어 TV 드라마, 광고, 다양한 콘텐 츠 등을 통해 수많은 연예인, 스포츠 스타들이 가장 아름답고 능력 있는 것으로 포장되어 전파를 타고 있다. 실제 많은 청소 년들이 장래 희망을 연예인이라고 이야기하듯이 유아들도 아 름답고 능력 있는 대상으로 텔레비전을 통해 접하는 스타를 꼽기도 하고 이들의 신체와 외모가 가장 이상적인 모습이라 고 생각하고 그렇게 되는 것을 미래의 목표나 기대로 받아들 이는 경향이 있다. 이러한 미디어 환경을 고려한다면 유아가 보이는 신체에 대한 가치 판단이 미디어의 영향을 받을 것으 로 예측할 수 있다. 그러나 미디어 요인이 미치는 영향, 구체적 으로 연예인이 등장하는 텔레비전에 노출된 경험이나 횟수가 유아의 신체상에 미치는 영향을 살펴본 연구는 거의 이루어지 지 않은 실정이다. 또한 이러한 연구가 학령기 아동과 청소년 을 대상으로 한 연구(Cho \& Kim, 2008; Dohnt, \& Tiggemann, 2006a; Oliver \& Thelen, 1996; Sands, \& Wardle, 2003)에 편중되 어 있어 유아의 신체인식에 영향을 미치는 미디어의 영향에 대한 심도 있는 고찰이 요구된다.

이러한 선행연구 고찰을 토대로 본 연구에서는 4,5 세 유아 의 신체인식이 어떠한지 살펴보고 유아의 신체인식에 유아 개 인요인(성별, 체질량지수), 어머니 요인(어머니 자신의 신체인 식, 어머니의 자녀 신체에 관한 언어적 상호작용), 유아의 미 디어 노출이 어떠한 영향을 미치는지 확인하고자 한다.

이에 따른 연구문제는 다음과 같다.

\section{연구문제 1}

유아의 신체인식, 신체특성(신체질량지수), 어머니의 신체인 식 및 자녀 신체에 관한 언어적 상호작용, 유아의 미디어 노출 간의 관계는 어떠한가?

\section{연구문제 2}

유아의 개인요인(성별, 신체질량지수), 어머니 요인(어머니 신 체인식, 자녀의 신체에 관한 언어적 상호작용), 유아의 미디어 노출이 유아의 신체인식에 미치는 영향은 어떠한가?

\section{연구방법}

\section{연구대상}

본 연구에서는 한국의 2 개 대도시 5 개 어린이집 및 유치원에 다니는 만 4,5 세 유아와 유아의 어머니 가운데 연구참여에 동 의한 유아 100 명과 그 어머니 100 명을 대상으로 조사를 실시 하였다. 유아의 연령을 4,5 세로 한정한 이유는 예비조사를 통 해 3 세 유아가 신체에 대한 개념과 자신의 신체 평가 조사에 참여하는 것이 어렵다고 판단되었기 때문이다. 연구 참여에 동의한 유아 가운데 결석으로 조사에 참여하지 못한 유아와 연령 기준에 부합하지 못한 유아를 제외하고 총 97 명의 유아 와 그 어머니 97명의 자료가 분석에 사용되었다. 전체 유아는 남아 47명(48.5\%), 여아 50명(51.5\%)으로 평균 나이는 61.8개 월이었으며, 어머니의 평균 연령은 36.58세였다.

전체 대상자의 사회인구학적 특성은 Table 1 과 같다. 부모 의 교육수준은 아버지의 $75 \%$, 어머니의 $72.1 \%$ 가 학사학위 이 상의 교육수준을 나타냈고 취업모의 비율이 $54.6 \%$ 였다. 또한 전체 가구의 $82.4 \%$ 이상이 중간 이상의 소득수준을 나타냈다.

\section{연구도구}

\section{신체인식}

유아와 어머니의 신체인식을 평가하기 위하여 Stunkard, Sorenson과 Schulsinger (1983)가 성인의 신체 인식 도구로 개발 한 신체 실루엣 그림을 수정하여 아동용과 성인용으로 제작한 도구를 기초로 그림카드 척도를 제작하여 사용하였다. 이 척 도는 자신의 신체 타입과 이상적 신체 타입을 평가하여 이 차 이를 신체에 대한 부정적 인식 수준으로 평가하였다. 이 척도 
Table 1

Demographic Characteristics of Participants

\begin{tabular}{lc}
\hline \multicolumn{1}{c}{ Classification } & $N(\%)$ \\
\hline Children's age (mo), $M \pm S D$ & $61.8 \pm 7.11$ \\
Children's gender & $47(48.5)$ \\
Male (boy) & $50(51.5)$ \\
Female (girl) & $36.58 \pm 4.08$ \\
\hline Mothers' age (yr), $M \pm S D$ & \\
\hline Mothers' education & $27(27.8)$ \\
High school graduate & $59(60.8)$ \\
College graduate & $11(11.3)$ \\
Graduate school & $53(54.6)$ \\
Employed mothers & $39.56 \pm 4.70$ \\
Father's age (yr), $M \pm S D$ & \\
Father's education & $24(24.7)$ \\
High school graduate & $55(56.7)$ \\
College graduate & $17(17.5)$ \\
Graduate school & $15(15.5)$ \\
Household's socioeconomic status & $50(51.5)$ \\
Low & $30(30.9)$ \\
Medium & \\
High &
\end{tabular}

Note. $N=97$. Household socio-economic status was divided by household income per month (Low = less than 3 million won; Medium = 3 -6 million won; High $=$ more than 6 million won $)$.

의 적절성을 확인하기 위하여 아동학 전공자 3 인과 보육교사 2 인의 검토를 거친 뒤에 만 5 세 유아 5 명과 어머니를 대상으 로 예비조사를 실시하였다. 아동학 전공자 3 인이 평정한 신체 인식 검사의 신뢰도는 .93으로 양호한 편이었다.

유아 신체인식 유아의 신체인식은 Stunkard 등(1983)이 사용 한 신체상 평가 척도의 신체 실루엣 그림을 아동용으로 제작 한 Collins(1991)와 Hendy 등(2001)의 신체상 평가 그림척도 를 기초로 제작하였다. 그림척도는 성별에 따라 두 세트로 준 비하여 조사대상 유아의 성별과 일치하는 그림척도를 이용하 여 조사를 실시하였다. 이 척도는 가장 마른 신체의 유아 그림 (1점)부터 가장 신체가 큰(살이 찐) 유아의 그림(7점)까지 신체 크기가 커짐에 따라 점수가 증가하는 형태로 구성되어있다. 조사자가 제시한 그림카드에서 유아는 현재 자신의 모습과 가 장 유사한 그림을 선택함으로써 현재 지각한 신체를 평가하고 이어서 가장 잘생기거나 예쁘다고 생각하는 그림을 선택해서 가장 이상적인 신체를 평가한다. 현재 신체 타입과 이상적 신 체 타입의 차이는 신체에 대한 부정적 인식 정도를 나타내며
점수 범위는 0-6점이다.

어머니 신체인식 어머니의 자신의 신체에 대한 인식은 Stunkard 등(1983)이 사용한 신체실루엣 그림을 토대로 제작 한 Thompson과 Gray (1995)의 성인용 신체상 평가 척도(Bodyimage Assessment Scale)를 기초로 제작하여 조사를 실시하였 다. 어머니 신체인식 평가척도는 가장 마른 신체의 여성 그림 (1점)부터 가장 신체가 큰(살이 찐) 여성 그림(9점)까지 신체사 이즈가 커짐에 따라 점수가 증가하는 형태로 구성되어있다. 현재 자신의 모습과 가장 유사한 그림을 선택함으로써 현재 지각한 신체를 평가하고 이어서 가장 잘생기거나 예쁘다고 생 각하는 그림을 선택해서 가장 이상적인 신체를 평가한다. 유 아의 신체인식 평가 척도와 마찬가지로 현재 자신과 가장 유 사한 신체타입과 이상적인 신체 타입을 선택하여 점수차이를 자신의 신체에 대한 부정적 인식 수준으로 평가하였다. 부정 적 신체인식 수준의 점수 범위는 0-8점이다.

\section{유아 체질량지수(Body Mass Index)}

유아의 신체특성을 신장과 체중을 모두 고려하여 비교하기 위 하여 체질량지수를 이용하였다. 체질량지수는 비만도를 나 타내는 지수로 신장과 체중을 이용하여 계산한다(Centers for Disease Control and Prevention [CDC], 2017). 유아의 신장과 체 중은 어린이집에서 담임교사가 측정하였다. 측정된 신장과 체 중 수치를 체질량지수의 계산법에 따라 점수를 낸 후 비교를 위해 표준화 점수로 산출하여 이용하였다. 체질량지수의 계산 법은 체중 $(\mathrm{kg}) /[\text { 신장 }(\mathrm{m})]^{2}$ 이다.

\section{어머니의 자녀 신체에 대한 언어적 상호작용}

어머니의 신체에 대한 언어적 상호작용 수준을 측정하기 위하 여 Hendy 등(2001)이 개발한 신체에 관한 메시지 빈도를 측정 하는 척도를 사용하였다. 이 척도는 "살빼려면 적게 먹어라.", "좀 너무 살이 쪘다.” 등 마른 신체가 되도록 강조하는 메시지 와 “더 크고 강해지려면 더 먹어라.", "너무 말랐다.” 등 더 큰 (살이 찐) 신체가 되도록 강조하는 메시지의 2 개의 하위 영역 으로 구성되어있다. 2 개의 하위영역은 각 3 개의 문항으로 구 성되어있고 전혀 하지 않는다(1점)에서 많이 한다(3점)의 순 으로 평정되는 3점 리커트 척도로 점수가 높을수록 메시지의 빈도가 높은 것을 의미한다. 이 척도의 Cronbach's $\alpha$ 값은 .57 과 .85로 신뢰할만한 수준이었다. 


$$
\text { 유아의 미디어 노출 }
$$

유아의 미디어 노출은 Dohnt와 Tiggemann (2006a)의 미디어 영향력 평가 방법을 수정하여 사용하였다. 이 척도는 미디어 경험을 측정하기 위하여 아동에게 인기 있는 만화영화나 예 능 프로그램 가운데 신체에 관한 메시지가 포함된 TV 프로그 램을 선정하여 이에 대한 아동의 시청 빈도를 평가하는 도구 이다. 본 연구에서는 아동학 전공자 3 인과 신문방송학 전공자 1 인이 논의하여 신체적 매력을 강조하는 유아에게 인기 있는 만화 또는 예능 TV 프로그램으로 10 개의 프로그램을 선정하 고 예비조사를 통해 최종적으로 5개의 프로그램(예: 리틀 프 린세스 소피아, 짱구는 못 말려 등)을 선정하였다. 이 척도는 안 본다(1점)에서 자주 본다(3점) 순으로 평정하는 3점 리커트 척도로 유아의 어머니는 질문지를 통해 이들 프로그램에 대한 자녀의 시청 빈도를 평정하였다. 이 척도의 Cronbach's $\alpha$ 값은 .72 로 나타났다.

\section{연구절차}

예비조사는 2016년 12월 첫째 주에 만 3세 유아 5명, 만 4, 5세 유아 5 명과 유아 자녀를 둔 어머니 10 명을 대상으로 실시하였 다. 3 세 유아를 대상으로 한 조사에서 3 세 유아가 신체에 대한 인식 과제를 수행하기 어려워 조사 대상을 4, 5세 유아로 한 정하였다. 그리고 예비조사 결과를 바탕으로 질문지의 문항 을 이해하기 쉽게 수정하고 아동학 전공자 및 보육교사 5 인의 검토를 거쳐 질문지를 구성하였다. 전체 연구는 호남대학교 생명윤리위원회의 연구윤리 심의를 거쳐 승인을 받았고(IRB
No. 1041223-201701-HR-034) 연구참여에 동의한 유아와 그 어머니를 대상으로 2017년 1월 25일부터 4주에 걸쳐 본조사 를 실시하였다. 먼저 연구참여에 동의한 어머니를 대상으로 설문지를 배포한 이후에 수거하였고, 부모의 동의를 받은 유 아를 대상으로 훈련받은 조사자 1 명이 유아와 일대일 면접을 실시하였다.

\section{자료분석}

수합된 자료는 SPSS ver. 18.0 (SPSS Inc., Chicago, IL) 프로그램 을 이용하여 변인의 전반적인 경향을 살펴보기 위하여 기술 통계분석을 실시하였다. 그리고 주요 변인들 간의 관계를 살 펴보기 위하여 상관분석을 실시하였으며, 사회인구학적 변인 을 통제하고 유아 개인 요인과 어머니 요인, 유아의 미디어 노 출이 유아 신체인식에 미치는 영향을 살펴보기 위하여 위계적 회귀분석을 실시하였다.

\section{연구결과}

\section{유아의 신체인식과 신체특성, 미디어노출 및 어머니의 신체인식과 자녀 신체에 관한 언어 적 상호작용의 일반적 경향}

주요 변인의 전반적인 경향을 살펴보기 위하여 기술통계분 석을 실시한 결과는 Table 2 와 같다. 먼저 유아가 자신의 신체 에 부정적으로 인식하는 정도인 유아의 신체인식 점수는 1.68

Table 2

Descriptive Statistics of Main Variables

\begin{tabular}{|c|c|c|c|}
\hline Variables & $\begin{array}{c}\text { Total }(n=97) \\
M(S D)\end{array}$ & $\begin{array}{c}\text { Boy }(n=47) \\
M(S D)\end{array}$ & $\begin{array}{c}\text { Girl }(n=50) \\
M(S D)\end{array}$ \\
\hline Children's body perception & $1.68(1.22)$ & $1.32(1.04)$ & $2.02(1.29)$ \\
\hline \multicolumn{4}{|l|}{ Individual factors } \\
\hline Heights (cm) & $109.06(6.95)$ & $109.59(7.85)$ & $108.57(6.03)$ \\
\hline Weights (kg) & $19.42(3.73)$ & $19.60(4.25)$ & $19.25(3.21)$ \\
\hline BMI z-score & $0.38(1.19)$ & $0.29(1.32)$ & $0.46(1.05)$ \\
\hline \multicolumn{4}{|l|}{ Maternal factors } \\
\hline Body perception & $1.78(1.20)$ & $1.72(1.05)$ & $1.84(1.33)$ \\
\hline Verbal message to "be bigger" & $2.09(0.56)$ & $2.07(0.53)$ & $2.11(0.58)$ \\
\hline Verbal message to "be thinner" & $1.27(0.54)$ & $1.16(0.42)$ & $1.37(0.62)$ \\
\hline Children's media exposure & $1.40(0.34)$ & $1.20(0.23)$ & $1.59(0.32)$ \\
\hline
\end{tabular}

Note. Body mass index (BMI) is a value derived from the mass (weight) and height of a child. BMI is calculated as the body mass divided by the square of the body height. 
$(S D=1.22)$ 로 낮은 편이었다. 다시 말해 연구대상 유아는 전반 적으로 자신의 신체를 이상적으로 받아들이는 편이었다. 여아 와 남아의 신체인식 점수에서는 여아가 남아보다 상대적으로 자신의 신체를 부정적으로 인식하는 편이었다. 어머니의 신체 인식 점수도 낮은 편이었는데 전반적으로 신체에 대해 긍정적 으로 인식하는 것으로 나타났다.

유아의 실제 신체 발달 수준을 확인하기 위하여 유아의 신 장과 체중을 이용하여 비만도를 나타내는 체질량지수(BMI) 를 산출한 결과 평균 $\mathrm{BMI}$ 점수는 $0.38(S D=1.19)$ 로 나타났 다. $\mathrm{BMI}$ 점수를 표준화하여 유아의 신체 유형을 분류하고자 미국질병관리본부(Centers for Disease Control and Prevention [CDC], 2017)에서 제공한 BMI 표준화점수 산출방법을 활용 하여 표준화 점수를 산출하였다. 그리고 질병관리본부와 대 한소아과학회에서 제공한 한국 소아청소년 성장 도표(Korea Centers for Disease Control \& Prevention \& The Korean Pediatric Society, 2007)를 이용하여 조사대상 유아를 3 개 유형으로 분류 한 결과 전체 유아의 $60.8 \%$ 는 표준형이었고 $16.5 \%$ 가 비만형, $22.7 \%$ 가 왜소형으로 나타났다. 즉, 다수의 유아가 표준적인 신체발달 수준을 보였다.

어머니가 자녀에게 하는 신체에 관한 언어적 상호작용 점 수는 매우 낮았는데 상대적으로 살을 찌우라는 말을 하는 빈 도 수준이 더 높게 나타났다. 그리고 여아 어머니가 남아의 어 머니보다 살을 빼거나 찌우라는 말을 하는 빈도가 약간 더 많 은 것으로 나타났다. 유아의 미디어 노출 경험도 낮은 수준이 었는데, 여아가 남아보다는 신체적 매력을 강조하는 TV 프로 그램 시청 경험 수준이 약간 높았다.

\section{유아의 신체인식과 신체특성, 미디어노출 및 어머니의 신체인식과 자녀 신체에 관한 언어 적 상호작용 간의 관계}

유아의 신체인식과 신체특성인 BMI, 미디어노출과 어머 니의 신체인식, 어머니의 자녀 신체에 관한 언어적 상호작용 간의 상관관계를 알아보기 위하여 상관분석을 실시한 결과는 Table 3과 같다.

먼저 유아의 미디어 노출과 신체적 인식은 유의미한 정적 상관이 있는 것으로 나타났다 $(r=.23, p<.05)$. 다시 말해 유아 의 미디어 노출과 유아가 자신의 신체에 대해 부정적으로 인 식하는 수준은 정적으로 관련이 있었다. 반면에 유아의 BMI 나 어머니의 신체인식, 자녀 신체에 관한 언어적 상호작용은 유아의 신체인식과 상관관계가 나타나지 않았다. 한편 유아의 $\mathrm{BMI}$ 점수와 어머니의 자녀 신체에 한 언어 메시지 중에 '살을 빼라'는 체중 감소를 강조하는 언어메시지 빈도가 정적으로 관련이 있었다 $(r=.50, p<.01)$.

\section{유아 개인요인, 어머니 요인, 유아의 미디어 노출이 유아의 신체인식에 미치는 영향}

유아의 개인요인인 성별, BMI와 어머니 요인인 어머니 신체 인식, 어머니의 자녀 신체에 관한 언어적 상호작용, 유아의 미 디어 노출이 유아의 신체인식에 미치는 영향을 살펴보기 위하 여 회귀분석을 실시하였다. 사회인구학적 변인의 영향을 통제 하고 이들 변인이 유아의 신체인식에 미치는 상대적 영향력을 살펴보기 위하여 먼저 1단계에서 사회인구학적 변인인 가정 의 월소득수준, 어머니의 교육수준과 취업여부를 통제변인으 로 투입하고 2단계에서는 유아의 성별, BMI, 어머니의 신체인 식과 자녀의 신체에 대한 언어적 상호작용, 유아의 미디어 노 출을 투입하여 위계적 회귀분석을 실시하였다. 독립변인들 간 의 다중공선성 여부를 판단하기 위하여 분산팽창요인(VIF)을 살펴본 결과, $1.05-1.82$ 로 10 을 넘지 않았으며 더빈왓슨값도 1.88 로 다중공선성의 위험은 없는 것으로 나타났다. 위계적 회귀분석 결과는 Table 4 와 같다.

Table 3

Correlations Among Children's Body Perception, BMI, Media Exposure, Mothers'Body Perception and Verbal Messages on Children's Body

\begin{tabular}{|c|c|c|c|c|c|c|}
\hline & 1 & 2 & 3 & 4 & 5 & 6 \\
\hline 1. Children's body perception & - & & & & & \\
\hline 2. BMI & -.14 & - & & & & \\
\hline 4. Mothers' verbal message to "be bigger" & .06 & .08 & .08 & - & & \\
\hline 5. Mothers' verbal message to "be thinner" & .15 & $.50^{* *}$ & .00 & .16 & - & \\
\hline
\end{tabular}

${ }^{*} p<.05 .{ }^{* *} p<.01$. 
Table 4

Effect of Children's Individual Factors, Maternal Factors, and Children's Media Exposure on Children's Body Perception

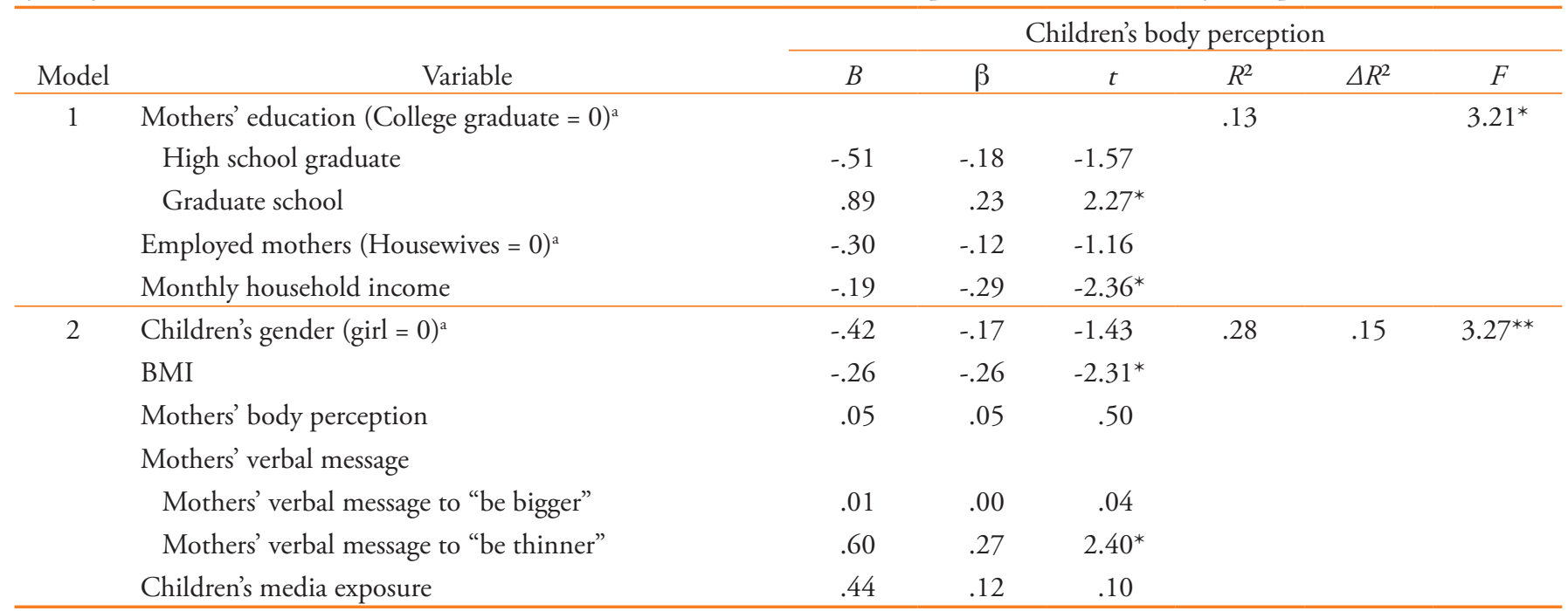

Note. ${ }^{\text {a }}$ Dummy variable.

${ }^{*} p<.05 .{ }^{* *} p<.01$.

분석을 실시한 결과 최종회귀모형은 유의미한 것으로 나타 났으며, 유아의 신체인식에 대한 설명력은 $28 \%$ 로 나타났다 $(F$ $=3.27, p$ < .01). 먼저 1단계에서 통제변인을 투입한 결과 회귀 모형 1 은 유의미하였다 $(F=3.21, p<.05)$. 설명력은 $13 \%$ 로 나타 났으며 가정의 소득수준 $(\beta=-2.36, p<.01)$ 과 어머니의 학력 $(\beta=$ $2.27, p<.01)$ 이 유아의 신체인식에 영향을 미치는 유의미한 변 인으로 나타났다. 이어서 유아 개인요인, 어머니요인, 유아의 미 디어 노출 변인이 투입된 2단계 회귀모형에서는 유아 신체인식 에 미치는 영향력이 $15 \%$ 증가하였다. 이들 변인 가운데 어머니 의 자녀 신체에 대한 언어적 상호작용 가운데 '살을 빼라'라는 언어메시지 $(\beta=2.40, p<.05)$ 와 유아의 BMI $(\beta=-2.31, p<.05)$ 가 유아의 신체인식에 영향을 미치는 것으로 나타났다.

\section{논의 및 결론}

본 연구에서는 4-5세 유아의 신체상과 이에 영향을 미치는 요인 을 살펴보기 위하여 유아의 개인요인(성별, $\mathrm{BMI}$ )과 어머니 요 인(어머니 신체인식, 어머니의 자녀 신체에 대한 언어적 상호작 용), 유아의 미디어 노출이 유아의 신체인식에 미치는 영향을 알아보고자 하였다. 주요 연구결과를 논의하면 다음과 같다.

첫째, 조사에 참여한 4,5 세 유아의 신체에 대한 부정적 인식 은 낮은 수준이었다. 다시 말해 자신의 실제 신체와 이상적이라 고 지각하는 신체와의 차이가 크지 않아 전반적으로 자신의 신
체를 긍정적으로 인식하는 것으로 나타났다. 유아의 신체특성 인 $\mathrm{BMI}$ 를 살펴본 결과 조사 대상 유아의 다수가 표준적인 체형 을 가진 것으로 나타났다. 그리고 유아의 신체인식에서는 여아 의 신체에 대한 부정적 인식 수준이 남아보다 약간 높았다.

둘째, 주요 변인인 유아 신체인식과 유아 개인 요인, 어머니 요인, 유아 미디어 노출 간의 관계를 살펴본 결과, 유아의 미 디어 노출 빈도와 유아의 신체에 대한 부정적 인식 수준이 정 적 상관이 있었다. 미디어 노출 빈도 횟수가 높을수록 유아의 부정적 인식 수준이 높은 것으로 나타났다. 이러한 결과는 아 동과 청소년을 대상으로 미디어 시청 경험 수준과 신체만족도 를 살펴본 선행연구의 결과와 일치한다(Dohnt \& Tiggemann, 2006a; Thompson et al., 1999). 그리고 유아의 BMI와 어머니의 자녀 신체에 대해 '살빼라’라는 언어적 메시지 빈도가 정적 상 관이 있는 것으로 나타났다. BMI 점수가 증가한다는 것은 비 만도가 높아지는 것을 의미하며 대부분의 유아가 표준 체형임 에도 불구하고 $\mathrm{BMI}$ 가 증가할수록 어머니가 유아기 자녀에게 도 언어적으로 신체에 대한 평가나 체중과 관련된 말을 더 많 이 할 수 있다는 것을 의미한다.

셋째, 위계적 회귀분석을 실시한 결과, 통제 변인인 사회인 구학적 변인 가운데 어머니의 학력이 유아의 자기 신체에 대 한 부정적 인식에 영향을 미치는 요인으로 나타났다. 특히 어 머니의 학력이 대학원 졸업의 고학력일수록 그렇지 않은 경우 에 비해 자녀의 신체에 대한 부정적 인식이 높은 경향이 있었 다. 또한 소득수준도 유아의 부정적인 신체인식을 예측하는 
요인이었는데 소득수준이 높을수록 유아의 신체에 대한 부정 적 인식 수준은 낮은 것으로 나타났다. 우리나라 유아를 대상 으로 어머니의 교육수준이나 소득수준과 신체상과의 관련성 을 살펴본 선행연구가 없으므로 이러한 결과를 해석하는데 있 어서 주의할 필요가 있다. 학령기 아동과 청소년을 대상으로 사회경제적 지위, 부모의 교육수준 등의 변인과 신체상의 관 련성을 살펴본 국외의 선행연구(O'dea \& Caputi, 2001; Soba \& Stunkard, 1989)에 따르면 소득수준이나 부모의 교육수준 등 이 자녀의 신체상 형성에 영향을 줄 수 있으나 이것은 이상적 인 신체에 대한 문화적 편견이나 가족 내의 대화, 자녀의 성별 에 따라 달라질 수 있다고 보고하였다. 예를 들어 미국에서는 과체중이 중상류층 여아에게는 낮은 신체적 자존감을 야기하 지만 하류층 남아에게는 높은 신체자존감을 갖는 요인이 될 수도 있다. 따라서 추후 연구에서는 이러한 다양한 요인 간의 상호작용에 초점을 맞추어 우리나라 아동의 신체상에 영향을 미치는 요인을 살펴볼 필요가 있다.

넷째, 사회인구학적 변인을 통제한 이후에 유아 개인 요인 과 어머니 요인, 유아의 미디어 노출이 유아 신체인식에 미치 는 영향을 살펴본 결과, 유아의 BMI와 어머니가 자녀에게 체 중감소를 강조하는 언어 메시지가 유아의 신체인식에 유의미 한 영향을 미치는 것으로 나타났다. 먼저, 유아의 BMI가 증가 할수록 자신의 신체를 부정적으로 인식하는 정도는 낮은 것으 로 나타났다. 이러한 결과는 연령이 더 많은 아동을 대상으로 한 선행연구(Dohnt \& Tiggemann, 2006a; McCabe et al., 2006) 에서 $\mathrm{BMI}$ 와 부정적 신체상과의 부적 관련성을 보고한 것과는 상반된 결과이다. 그러나 유아가 아직은 객관적이거나 사회적 인 기준에 따라 자신의 신체 크기를 지각하는 것이 어려워 실 제 신체 크기 자각과 신체 평가와는 관련이 없다는 선행연구 (Musher-Eizenman et al., 2003)와 유사한 맥락으로 볼 수 있다.

두 번째로 어머니가 자녀의 체중감소를 강조하는 말을 많 이 할수록 유아가 자신의 신체를 더 부정적으로 인식하는 경 향이 있었다. 이러한 결과는 어머니의 자녀의 외모나 신체 에 대한 평가가 자녀의 신체상에 미치는 영향을 입증한 선행 연구의 결과(Hendy et al., 2001; Pike \& Rodin, 1991; Sands \& Wardle, 2003; Striegel-Moore \& Kearney-Cooke, 1994; Vander Wal \& Thelen, 2000)와 일치한다. 반면에 어머니 자신의 신체 인식은 자녀의 신체인식에 영향을 미치지는 않는 것으로 나 타났다. 이것은 학령기 아동이나 청소년을 대상으로 한 연구 (Pike \& Rodin, 1991; Sands \& Wardle, 2003; Striegel-Moore \& Kearney-Cooke, 1994)에서 어머니 자신의 신체만족도나 섭식행 동이 모델링 역할을 하여 자녀에게 영향을 미친다고 보고한 연
구와는 다른 결과이지만 유아를 대상으로 한 Hendy 등(2001)의 연구에서 어머니의 자녀 신체에 대한 직접적인 평가만이 유아 기 자녀의 신체상에 영향을 미친다는 결과와는 일치한다.

Pike와 Rodin (1991)이 부모에 대한 모델링을 통해 신체상 의 전이와 학습이 이루어진다고 강조한 이래 부모 자신의 신 체상과 자녀의 신체 대한 평가 모두 자녀의 신체상 형성에 중 요한 역할을 하는 것으로 간주되었다. 그러나 이러한 과정이 발달적으로 차이가 있을 수 있다. 즉, 유아기에는 어머니가 보 이는 자녀의 섭식행동에 대한 관여나 평상시에 자녀의 신체에 대한 언어적 평가가 자녀의 신체인식에 더 영향을 미칠 수 있 다는 것을 의미한다. 자녀 신체에 대한 어머니의 지속적인 평 가는 유아기부터 어머니가 제시하는 기준에 맞추어 이상적인 신체상을 형성하게 만들 수 있으며 이는 자신의 실제 신체에 대한 만족감이나 자존감 형성에까지 영향을 미칠 수 있다. 따 라서 학령기 아동.청소년과 부모를 대상으로 한 신체자존감 강화나 건강한 신체상 형성을 위한 교육이 좀 더 이른 시기부 터 이루어질 필요가 있음을 시사한다. 유아기에 형성된 신체 상이 청소년기까지 안정적으로 유지되는지에 대해서는 논의 가 지속되고 있음에도 불구하고(Smolak, 2004), 자녀의 신체상 형성에 대한 어머니의 역할은 발달의 전 시기에 걸쳐 중요하 다. 이에 따라 유아 자녀의 부모를 대상으로 한 부모교육에서 도 외모와 신체에 대한 언어적 상호작용의 내용과 방법이 의 미 있게 다루어질 필요가 있다.

한편 유아의 성별이 신체인식에 미치는 영향은 유의미하지 않은 것으로 나타났다. 이러한 결과는 유아의 신체인식에서 성차가 없는 것으로 보고한 선행연구(Hendy et al., 2001; H.-Y. Kim et al., 2012)의 결과와 일치한다. 이것은 발달적으로 학령 기 이후에 나타나는 신체인식에서의 성차가 유아기에는 나타 나지 않는다는 것을 의미한다. 그리고 주요변인 간의 관계를 분석한 결과 유아의 미디어노출과 신체인식 간에 정적 상관 이 있었음에도 불구하고 미디어노출이 유아의 부정적 신체인 식에 미치는 영향은 유의미하지 않은 것으로 나타났다. 일부 선행연구(Damiano, Paxton, Wertheim, McLean, \& Gregg, 2015; Dohnt \& Tiggemann, 2006b)에 따르면 미디어 경험은 유아의 신체상에 직접 영향을 끼치지 않음에도 불구하고 유아의 섭식 에 대한 자각이나 섭식절제에 영향을 미치는 것으로 나타났 다. 따라서 추후 연구에서는 유아의 미디어 노출과 섭식행동 등 신체상 형성과 관련된 행동과의 관계를 함께 고려할 필요 가 있을 것이다.

본 연구는 유아의 개인 요인, 어머니 요인, 유아의 미디어 노 출이 유아의 신체인식에 미치는 영향을 확인함으로써 우리나 
라 유아의 신체상 발달의 기제를 확인했다는 점에서 의의가 있 다. 본 연구는 유아의 신체인식에 영향을 미치는 어머니 요인 으로 어머니가 자녀와 하는 신체에 대한 언어적 상호작용의 영 향을 입증함으로써 이른 시기부터 어머니가 자녀의 긍정적인 신체상 형성에서 중요한 역할을 한다는 점을 시사하고 있다. 또한 본 연구에서는 사회문화적 요인으로 미디어 경험을 다룸 으로써 현대사회에서 유아의 성장에 영향을 미칠 수 있는 외부 환경의 중요성을 환기시키는데 기여하였다. 본 연구에서 미디 어 경험을 노출 빈도에 한정했는데 추후 연구를 통해 동화, 비 디오, 스마트기기 콘텐츠 등 다양한 매체 경험을 포함한 사회 문화적 요인을 고찰해볼 수 있을 것이다. 지금까지 유아 대상 신체상 연구가 미흡한 시점에서 본 연구의 결과는 유아의 신체 적 자존감 강화 프로그램이나 이를 지지하기 위한 부모교육 프 로그램 구성을 위한 근거 자료로 활용될 수 있을 것이다.

이러한 의의에도 불구하고 본 연구가 가진 제한점은 다음 과 같다. 먼저 조사 대상자 수가 적기 때문에 결과를 일반화하 는데 주의를 요한다. 후속 연구에서는 연령별로 조사대상의 수를 추가하여 유아의 신체상 발달과 이에 영향을 미치는 요 인을 다각적으로 고찰할 필요가 있다. 또한 본 연구에서는 아 버지를 포함한 가정환경요인이 주요 변인으로 다루어지지 않 았다. McCabe와 Ricciardelli (2001)는 자녀의 성별에 따라 아버 지가 자녀의 신체상에 미치는 영향에 차이가 있다고 보고하였 는데, 후속연구에서 이러한 점을 보완하여 부모 및 다양한 가 족 변인을 함께 살펴보는 것도 의미가 있을 것이다.

\section{Acknowledgements}

This research was supported by the Ministry of Education of the Republic of Korea and the National Research Foundation of Korea (NRF-2016S1A5A8020105).

\section{Notes}

This article was presented at 2017 Academic International Conference on Multi-Disciplinary Studies and Education.

\section{Conflict of Interest}

No potential conflict of interest relevant to this article was reported.

\section{References}

\section{In English}

Bandura, A. (1997). Self-efficacy: The exercise of control. New York: Freeman.

Centers for Disease Control and Prevention. Child and teen BMI calculator. Retrieved from https://nccd.cdc.gov/dnpabmi/ Calculator.aspx

Collins, M. E. (1991). Body figure perceptions and preferences among preadolescent children. International Journal of Eating Disorders, 10(2), pp.199-208. doi:10.1002/1098108X(199103)10:2<199::AID-EAT2260100209>3.0.CO;2-D

Cramer P. \& Steinwert T. (1998). Thin is good, fat is bad: How early does it begin. Journal of Applied Developmental Psychology, 19(3), 429-451. doi:10.1016/S01933973(99)80049-5

Damiano, S. R., Paxton, S. J., Wertheim, E. H., McLean, S. A., \& Gregg, K. J. (2015). Dietary restraint of 5-year-old girls: Associations with internalization of the thin ideal and maternal, media, and peer influences. International Journal of Eating Disorders, 48(8), 1166-1169. doi:10.1002/ eat. 22432

Dohnt, H. K., \& Tiggemann, M. (2006a). Body image concerns in young girls: The role of peers and media prior to adolescence. Journal of Youth and Adolescence, 35(2), 141151. doi:10.1007/s10964-005-9020-7

Dohnt, H. K., \& Tiggemann, M. (2006b). The contribution of peer and media influences to the development of body satisfaction and self-esteem in young girls: A prospective study. Developmental Psychology, 42(5), 929-936. doi:10.1037/0012-1649.42.5.929

Engeln-Maddox, R. (2006). Buying a beauty standard or dreaming of a new life? Expectations associated with media ideals. Psychology of Women Quarterly, 30(3), 258-266. doi:10.1111/j.1471-6402.2006.00294.x

Hendy. H. M., \& Gustitus. C., \& Leitzel-Schwalm. J. (2001). Social cognitive predictors of body Image in preschool children. Sex Roles, 44(9-10), 557-569. doi:10.1023/ A:1012291008803

Kirkpatrick, S. W., \& Sanders, D. M. (1978). Body image stereotypes: A developmental comparison. The Journal of Genetic Psychology, 132(1), 87-95. doi:10.1080/00221325. 1978.10533317

Knafo, H. (2016). The development of body image in schoolaged girls: A review of the literature from sociocultural, social learning, psychoanalytic, and attachment theory perspectives. The New School Psychology Bulletin, 13(2), 1-16. Retrieved from https://www.nspb.net/index.php/ 
nspb/article/view/270/162

Marsh, H. W., Hau, K. T., Sung, R. Y., \& Yu, C. W. (2007). Childhood obesity, gender, actual ideal body image discrepancies, and physical self-concept in Hong Kong children: Cultural differences in the value of moderation. Deveopmental Psychology, 43(3), 647-662. doi:10.1037/0012-1649.43.3.647

McCabe, M. P., \& Ricciardelli, L. A. (2001). Parent, peer, and media influences on body image and strategies to both increase and decrease body size among adolescent boys and girls. Adolescence, 36(142), 225-240. Retrieved from https://www.ncbi.nlm.nih.gov/pubmed/11572302

McCabe, M. P., Ricciardelli, L. A., Stanford, J., Holt, K., Keegan, S., \& Miller, L. (2006). Where is all this pressure coming from? Messages from mothers and teachers about preschool children's appearance, diet and exercise. European Eating Disorders Review, 15(3), 221-230. doi:10.1002/erv.717

Musher-Eizenman, D. R., Holub, S. C., Edwards-Leeper, L., Persson, A. V., \& Goldstein S. E. (2003). The narrow range of acceptable body types of preschoolers and their mothers. Journal of Applied Developmental Psychology, 24(2), 259272. doi:10.1016/S0193-3973(03)00047-9

O'dea, J. A., \& Caputi, P. (2001). Association between socioeconomic status, weight, age and gender, and the body image and weight control practices of 6- to 19-year-old children and adolescents. Health Education Research, 16(5), 521-532. doi:10.1093/her/16.5.521

Oliver, K. K., \& Thelen, M. H. (1996). Children's perceptions of peer influence on eating concerns. Behavior Therapy, 27(1), 25-39. doi:10.1016/S0005-7894(96)80033-5

Phares, V., Steinberg, A. R., \& Thompson, J. K. (2004). Gender differences in peer and parental influences: Body image disturbance, self-worth, and psychological functioning in preadolescent children. Journal of Youth and Adolescence, 33(5), 421-429. doi:10.1023/B:JOYO.0000037634.18749.20

Pike, K. M., \& Rodin, J. (1991). Mothers, daughters, and disordered eating. Journal of Abnormal Psychology, 100(2), 198-204. doi:10.1037/0021-843X.100.2.198

Robinson T. N., Chang J. Y., Haydel, K. F. \& Killen, J. D. (2001). Overweight concerns and body dissatisfaction among thirdgrade children: The impacts of ethnicity and socioeconomic status. Journal of Pediatrics, 138(2), 181-187. doi:10.1067/ mpd.2001.110526

Sands, E. R., \& Wardle, J. (2003). Internalization of ideal body shapes in 9-12-year-old girls. International Journal of Eating Disorders, 33(2), 193-204. doi:10.1002/eat.10121

Slade, P. D. (1988). Body image in anorexia nervosa. The British Journal of Psychiatry, 153(Suppl 2), 20-22.

Smolak, L. (2004). Body image in children and adolescents: Where do we go from here? Body Image, 1(1), 15-28. doi:10.1016/ S1740-1445(03)00008-1
Soba, J., \& Stunkard, A. J. (1989). Socioeconomic status and obesity: A review of the literature. Psychology Bulletin, 105(2), 260-275. doi:10.1037/0033-2909.105.2.260

Stager, S. F., \& Burke, P. J. (1982). A reexamination of body build stereotypes. Journal of Research in Personality, 16(4), 435446. doi:10.1016/0092-6566(82)90004-6

Striegel-Moore, R. H., \& Kearney-Cooke, A. (1994). Exploring parent"s attitudes and behaviors about their children's physical appearance. International Journal of Eating Disorders, 15(4), 377-385. doi:10.1002/eat.2260150408

Stunkard, A. J., Sorensen, T., \& Schulsinger, F. (1983). Use of the Danish adoption register for the study of obesity and thinness. In S. Kety, L. P. Rowland, R. L. Sidman, \& S. W. Matthaysse (Eds.), The genetics of neurological and psychiatric disorders (pp. 115-120). New York: Raven Press.

Thelen, M. H., Powell, A. L., Lawrence, C., \& Kuhnert, M. E. (1992). Eating and body image concerns among children. Journal of Clinical Child Psychology, 21(1), 41-46. doi:10.1207/ s15374424jccp2101_7

Thompson, J. K., Heinberg, L. J., Altabe, M., \& Tantleff-Dunn, S. (1999). Exacting beauty: Theory, assessment, and treatment of body image disturbance. Washington, DC: American Psychological Association.

Thompson, M. A., \& Gray, J. J. (1995). Development and validation of a new body-image assessment scale. Journal of Personality Assessment, 64(2), 258-269. doi:10.1207/ s15327752jpa6402_6

Tremblay, L., \& Limbos, M. (2009). Body image disturbance and psychopathology in children: Research evidence and implications for prevention and treatment. Current Psychiatry Reviews, 5(1), 62-72. doi:10.2174/157340009787315307

Vander Wal, J. S., \& Thelen, M. (2000). Predictors of body image dissatisfaction in elementary-age school girls. Eating Behaviors, 1(2), 105-122. doi:10.1016/S14710153(00)00011-8

Veldhuis, J., te Poel, F., Pepping, R., Konijn, E. A., \& Spekman, M. L. C. (2017). "Skinny is prettier and normal: I want to be normal"-Perceived body image of non-Western ethnic minority children in the Netherlands. Body image, 20, 7486. doi:10.1016/j.bodyim.2016.11.006

\section{In Korean}

Cho, Y.-K., \& Kim, E.-M. (2008). Effects of the media, peers and parents on adolescents' thin-ideal internalization and the body satisfaction. Korean Journal of Journalism o Communication Studies, 52(5), 255-274.

Jang, J. (2016, March 2). Incheon cheongsonyeon 67.7\% stress nochul[인천 청소년 $67.7 \%$ 스트레스 노출]. Incheon Ilbo. Retrieved from http://www.incheonilbo.com/?mod=news\& 
act $=$ articleView $\&$ idxno $=696128 \# 08 \mathrm{hF}$

Jang, H.-S. \& Kim, T.-R. (2006). The effect of mass media on body perception and state esteem of body image. Studies on Korean Youth, 17(2), 57-83.

Kim, H.-J., Kim, J.-Y., \& Kim, K.-S. (2012). Analysis of young children's perceptions and experiences of appearance and body type. Early Childhood Education Research \& Review, 16(5), 209-231.

Kim, H.-Y., Kim, Y.-H., \& Kim, K.-S. (2012). Relationships among young children's socio-cultural attitudes toward appearance, body esteem, peer acceptance, and social competence. Journal of Early Childhood Education, 32(4), 73-91.

Park, E.-H. \& Lee, S.-H. (2010). Understanding the body image of 5-year-old children. Early Childhood Education Research \& Review, 14(1), 227-252.
Korea Centers for Disease Control \& Prevention \& The Korean Pediatric Society (2007). 2007 Soacheongsonyeon pyojunseongjangdopyo[2007년 소아청소년 표준성장도표]. Retrieved from KCDC website: http://www.cdc.go.kr/

$\begin{array}{ll}\text { Insuk Choi } & \text { http://orcid.org/0000-0003-1140-6017 } \\ \text { Jisoo Im } & \text { http://orcid.org/0000-0002-8391-3029 }\end{array}$

Received March 31, 2018 Revision received June 15, 2018

Accepted July 30, 2018 